\title{
MANUTENÇÃO DA UMIDADE DOSUBSTRATO DURANTE O TESTE DE GERMINAÇÃO DE Brachiaria brizantha ${ }^{l}$
}

\author{
CAROLINA MARIA GASPAR-OLIVEIRA² ${ }^{2}$ CIBELE CHALITA MARTINS ${ }^{3}$, \\ JOÃO NAKAGAWA ${ }^{4}$, CAMILA DE AQUINO TOMAZ 5
}

\begin{abstract}
RESUMO - Para avaliar procedimentos para a manutenção da umidade do substrato durante o teste de germinação de Brachiaria brizantha. Estudou-se o efeito da posição das caixas plásticas na câmara de germinação sobre a perda de água semanal, testando-se nove posições verticais (bandejas) e três posições horizontais (porta, meio e fundo do germinador). Foi também avaliado o efeito de procedimentos para manter a umidade do substrato, sobre a germinação, a perda de água semanal e o tempo despendido para a instalação do teste. Os procedimentos testados foram: (a) vedação da caixa plástica com vaselina, (b) vedação com saco plástico dobrado em quatro e colocado entre a tampa e a caixa, (c) colocação da caixa tampada dentro de saco plástico, (d) espuma sob o papel de germinação e (e) testemunha, caixa apenas tampada. Concluiuse que a câmara de germinação promove a desidratação desigual do substrato conforme a posição das caixas; aquelas localizadas na primeira bandeja superior são as mais prejudicadas. Entre os procedimentos, a vedação com vaselina, a colocação da caixa dentro de saco plástico e a vedação com saco plástico dobrado em quatro entre a tampa e a caixa são eficientes na manutenção da umidade do substrato em taxas que não alteram os resultados do teste de germinação de $B$. brizantha; os dois últimos procedimentos são os mais rápidos e práticos, adaptando-se à rotina de um laboratório de análise de sementes.
\end{abstract}

Termos para indexação: Germinador, perda de água, sementes, braquiária.

\section{MAINTENANCE OF SUBSTRATE MOISTURE DURING Brachiaria brizantha GERMINATION TEST}

\begin{abstract}
The research aimed to evaluate procedures for maintaining paper substrate moisture during Brachiaria brizantha germination test. So, the effect of plastic boxes position in a germination cabinet on weekly loss of substrate moisture was determined; nine vertical positions (trays) and three horizontal positions on the trays (front door, middle and back of the cabinet) were evaluated. The efficiency of some procedures for maintaining substrate moisture on germination percentage, weekly loss of substrate moisture and time spent for setting up the test was also studied. The procedures were as follows: (a) sealing the box by spreading vaseline in the surfaces between the lid and the box, (b) sealing the box by placing a plastic foil folded twice between the lid and the box, (c) placing the box, with the lid on, inside a plastic bag, (d) placing a polyethylene foam at the bottom of the box under the paper substrate and putting the lid on, and (e) control treatment, with just the lid on, without subsequent watering. It was concluded that the germination cabinet causes different dehydration rates of the substrates, and the boxes located on the first tray at the top are the most affected. Among the procedures, sealing the box with vaseline, placing the box inside a plastic bag and sealing the box by placing a plastic bag folded twice, are efficient for maintaining the paper substrate moisture at adequate levels in such a way that the results of Brachiaria brizantha germination tests are not altered; the last two mentioned procedures are faster and more practical, being easily adaptable to routine tests of a seed laboratory.
\end{abstract}

Index terms: germinator, water loss, seeds, signalgrass.

\footnotetext{
Submetido em: 15/02/2007. Aceito para publicação em: 23/04/2007.

2 Aluna do curso de pós-graduação (Doutorado) - Departamento de Produção Vegetal - Faculdade de Ciências Agronômicas / UNESP - C.P. 237 - CEP 18603-970 - tel: (14) 3811-7161 - Botucatu/ SP - Brasil - Bolsista da CAPES, cmgaspar@ fca.unesp.br

3 Eng. Agr., Dr., Prof ${ }^{\text {a. }}$ Colaboradora - Depto. de Produção Vegetal - FCA/UNESP, cibele @ fca.unesp.br

4 Eng. Agr., Dr., Prof. Titular Aposentado - Depto. de Produção Vegetal - FCA/UNESP, secdamv@ fca.unesp.br

5 Aluna de pós-graduação (Mestrado) em Agricultura - FCA/UNESP, catomaz@ fca.unesp.br
} 


\section{INTRODUÇÃO}

O teste de germinação é um dos principais testes utilizados para avaliar a qualidade das sementes, fornecendo resultados que são empregados na comercialização de lotes, armazenamento de sementes e cálculos de taxa de semeadura. Assim a obtenção de resultados reproduzíveis e comparáveis entre laboratórios é necessária, e esta se torna possível com a padronização dos procedimentos do teste quanto à temperatura, luz, umedecimento e tipo de substrato, métodos de superação de dormência, duração do teste e métodos de avaliação da germinação (Marcos Filho et al., 1987).

Entretanto, os laboratórios de análise de sementes têm encontrado dificuldades na manutenção da umidade do substrato durante a condução do teste de germinação, observando-se que o substrato papel, acondicionado em caixas plásticas, pode apresentar secagem antes da conclusão do teste determinada pelas Regras para Análise de Sementes (Brasil, 1992), prejudicando a embebição das sementes e o desenvolvimento normal das plântulas. No Brasil, este fato foi verificado em trabalhos de pesquisa com sementes de cebola (Antoniolli et al., 1986), cerejeira (Albrecht et al., 1986), Acácia manguim Willd. (Lima e Garcia, 1996) e sementes peletizadas de tomate (Oliveira et al., 2001).

Assim, durante o teste de germinação, a desidratação do substrato pode ser causada pelo sistema de ventilação dos germinadores e pela temperatura alternada, que ocasiona a condensação da água sob a tampa da caixa plástica, facilitando a evaporação para a câmara (Liberal, 1963). Este processo é intensificado e altera mais seriamente os resultados quando o tempo necessário à conclusão do teste é relativamente longo, como ocorre para algumas espécies, por exemplo, Brachiaria brizantha (Hochst. ex A. Rich.) Stapf e Panicum maximum Jacq. para as quais o teste de germinação tem duração de 21 e 28 dias, respectivamente.

O déficit hídrico durante a germinação inibe o início do desenvolvimento da radícula e o alongamento do hipocótilo, prejudicando o desenvolvimento do eixo embrionário (Belcher, 1975). Este evento eleva a porcentagem de plântulas anormais, como foi verificado para sementes de milho (Engelhardt et al, 1966), arroz (Noronha et al, 1967), amendoim (Tanaka et al, 1991) e algodão (Dutra et al., 1995).
No entanto, o excesso de água também pode ser prejudicial à germinação das sementes, pois limita a entrada de oxigênio, diminui a respiração, provoca atrasos ou paralisações no desenvolvimento das plântulas, causando anormalidades, como a ausência de radicelas e a formação de plântulas hialinas, podendo resultar na morte das sementes (Marcos Filho et al., 1987; Carvalho e Nakagawa, 2000), como foi constatado para milho (Engelhardt et al, 1966; Phaneendranath, 1980), arroz (Noronha et al., 1967), girassol (Cseresnyes, 1979), sorgo (Phaneendranath, 1980) e capim colonião (Toledo e Pedreira, 1984).

Destaca-se que a aeração é restringida quando o substrato é umedecido demasiadamente, ao ponto de formar uma película de água em torno das sementes (Marcos Filho et al., 1987). Este fato pode ocorrer por ocasião do reumedecimento do substrato, recomendado pelas Regras para Análise de Sementes (Brasil, 1992) quando necessário e a critério do analista, para que haja umidade suficiente para o crescimento do embrião. Contudo, o desconhecimento da quantidade de água remanescente no substrato e da quantidade de água que deve ser adicionada ocasiona uma hidratação inadequada, a mais ou a menos, podendo resultar na desuniformidade das repetições do teste (Marcos Filho et al., 1987).

Assim, alternativas têm sido testadas para minimizar a perda de água por evaporação, como por exemplo, mantendo-se a umidade relativa dentro da câmara de germinação entre 90-95\%, utilizando-se umidificadores automáticos ou ainda, protegendo-se os substratos com um pano ou papel úmido (Marcos Filho et al., 1987). Ainda quando o teste de germinação é realizado em rolo de papeltoalha, a prática de se colocar os rolos dentro de sacos plásticos mantém a umidade do substrato (Amaral, 1984; Tanaka et al, 1991; Andrade e Pereira, 1994; e Dutra et al., 1995).

Na germinação sobre papel em caixas plásticas, algumas práticas para manter a umidade do substrato também foram eficientes, como por exemplo, vedar a tampa da caixa plástica com fita crepe de $3 \mathrm{~cm}$ de largura, constatado em Panicum maximum por Toledo e Pedreira (1984), ou a colocação de espuma de polietileno com espessura de $15 \mathrm{~mm}$, ocupando um terço da área total da caixa plástica, com uma folha de papel filtro por baixo e outra por cima da espuma, recomendado por Doni Filho et al. (1985), para Araucaria angustifolia. Para a 
germinação sobre papel em placas de petri, a colocação das placas dentro de sacos plásticos foi eficiente para manter a umidade do substrato, como observado por Engelhardt et al. (1966), na germinação de sementes de milho.

Entretanto, além de eficiente, o procedimento escolhido para manter a umidade do substrato no teste de germinação deve ser reproduzível, rápido e prático, para que possa se adequar à rotina de um Laboratório de Análise de Sementes.

Assim, este trabalho teve por objetivo avaliar: o efeito da localização das caixas plásticas em câmara de germinação sobre a perda de água do substrato e a eficiência de procedimentos para a manutenção da umidade do substrato no teste de germinação de sementes de Brachiaria brizantha e a adequação destes à rotina de um Laboratório de Análise de Sementes.

\section{MATERIAIS E MÉTODOS}

A pesquisa foi conduzida no Laboratório de Análise de Sementes do Departamento de Produção Vegetal da Faculdade de Ciências Agronômicas, da Universidade Estadual Paulista (UNESP), na Fazenda Experimental Lageado, em Botucatu - SP, em dois experimentos.

No primeiro experimento avaliou-se o efeito da posição das caixas plásticas no germinador sobre a perda de água do substrato. A câmara de germinação utilizada foi confeccionada a partir de cabine de refrigerador, adaptada para apresentar alternância de temperatura e luz, por meio de controles eletrônicos, marca "Marconi", modelo "MA 402". As dimensões internas são 500x350x1150mm e as externas são 600x600x1170mm, para largura, profundidade e altura, respectivamente.

A câmara apresenta quatro lâmpadas fluorescentes de $15 \mathrm{~W}$ cada, localizadas na parte central e interna da porta, dois ventiladores dispostos na posição vertical e localizados na parte superior, que impulsionam o ar para uma placa frontal e para o fundo da câmara, duas cubas plásticas, sendo uma entre os ventiladores e as bandejas e a outra abaixo de todas as bandejas, que são mantidas com água durante toda a condução do teste para manter alta a umidade relativa da câmara, e dois sensores de temperatura, tipo PT100, localizados na parte superior direita e na parte inferior da câmara, sendo a precisão da temperatura de trabalho de $\pm 0,1^{\circ} \mathrm{C}$.
Esta câmara possui capacidade para nove bandejas, que são aramadas e com espaço para colocar 12 caixas plásticas de germinação (tipo gerbox), em cada uma delas, sendo três no sentido da profundidade (porta, meio e fundo) que foram avaliadas como tratamentos (posições horizontais), e quatro no sentido da largura (esquerda, centro esquerda, centro direita e direita), as quais foram consideradas como repetições, em blocos. As bandejas foram numeradas de acordo com a posição vertical no germinador, em ordem crescente, de cima para baixo, assim a primeira estava localizada na parte superior, e a nona, na parte inferior da câmara.

As caixas plásticas transparentes (110x110x35mm), com duas folhas de papel mata-borrão umedecidas com 2,5 vezes a massa do papel de água destilada, foram mantidas no germinador em temperaturas alternadas de $15^{\circ} \mathrm{C}$ por 16 horas no escuro e $35^{\circ} \mathrm{C}$ por oito horas na luz, por 21 dias, sem as sementes.

Determinou-se a massa inicial de cada caixa plástica com a tampa e o substrato, após o umedecimento do mesmo (Massa inicial), e posteriormente, as caixas foram avaliadas semanalmente (Massa aos $n$ dias) até o término do teste, aos 21 dias. Utilizou-se balança de precisão de 0,001g. A porcentagem de perda de água semanal foi calculada através da fórmula:

$\%$ Perda de água aos $n$ dias $=($ Massa inicial - Massa aos $n$ dias) * 100/Massa da água colocada em cada caixa; sendo $n$ igual a 7, 14 e 21 dias.

O delineamento experimental empregado foi em blocos ao acaso. A análise estatística utilizou esquema fatorial 9x3 (posições verticais x posições horizontais), com quatro blocos e comparação de médias pelo teste de Tukey a 5\% de probabilidade. Os dados foram transformados em arcsen $(\mathrm{x} / 100)^{1 / 2}$ antes da análise, de acordo com as recomendações de Banzatto e Kronka (2006).

No segundo experimento avaliaram-se os procedimentos para a manutenção da umidade do substrato durante o teste de germinação. Utilizou-se um lote de sementes fiscalizadas de Brachiaria brizantha cv. Marandu, que foi homogeneizado, submetido ao assoprador pneumático e complementado por separação manual para a obtenção de sementes puras.

O grau de umidade das sementes foi avaliado pelo método da estufa a $105^{\circ} \pm 3^{\circ} \mathrm{C}$ por $24 \mathrm{~h}$ (Brasil, 1992) utilizando-se duas subamostras de $2,0 \mathrm{~g}$ de sementes. 
O teste de germinação foi conduzido com quatro repetições de 100 sementes, semeadas sobre duas camadas de papel mata-borrão, umedecidas com 2,5 vezes a massa do papel de água destilada, dentro de caixas plásticas transparentes (110x110x35mm) em temperaturas alternadas de $15^{\circ} \mathrm{C}$ por 16 horas no escuro e $35^{\circ} \mathrm{C}$ por oito horas na luz (Brasil, 1992). As contagens e retirada das plântulas normais foram efetuadas no sétimo, $14^{\circ}$ e $21^{\circ}$ dia após a instalação do teste. Durante o teste não houve reumedecimento do substrato, e periodicamente foi realizado o rodízio das caixas plásticas nas bandejas e destas no germinador.

Avaliou-se o efeito dos tratamentos sobre a velocidade de germinação por meio do teste da primeira contagem do teste de germinação, avaliado contabilizando-se as plântulas normais no sétimo dia após a semeadura.

Os procedimentos para a manutenção da umidade do substrato foram: (a) vedação com vaselina em volta da parte interna da tampa da caixa plástica (Figura 1), (b) vedação com saco plástico de 300x400mm e 0,05mm de espessura, dobrado em quatro, ou seja, uma camada de $0,40 \mathrm{~mm}$ de plástico, e colocado entre a tampa e a caixa plástica, de forma que a tampa ficasse bem fixa à caixa quando fechada (Figura 2), (c) colocação da caixa plástica tampada, individualmente, dentro de saco plástico de 200x300mm e 0,05mm de espessura (Figura 3), (d) utilização de uma camada de espuma de polietileno com $10 \mathrm{~mm}$ de altura e densidade de $20 \mathrm{mg} / \mathrm{cm}^{3}$, umedecida com $5 \mathrm{ml}$ de água sob o papel de germinação no fundo da caixa (Figura 4), e (e) testemunha, sem nenhum artifício para impedir a desidratação do substrato, nem mesmo o reumedecimento, tolerado pelas Regras para Análise de Sementes (Brasil, 1992) (Figura 5).

Determinou-se a massa de cada caixa plástica após o umedecimento do substrato e com o teste de germinação instalado, já com os procedimentos de manutenção de umidade (Massa inicial), com o auxílio de uma balança de precisão de $0,001 \mathrm{~g}$. Posteriormente as caixas foram avaliadas semanalmente, sendo que em cada leitura (sete, 14 e 21 dias) determinou-se a massa das caixas antes da retirada das plântulas (Massa aos $n$ dias antes), que representa a perda de água semanal e após a retirada das plântulas (Massa aos $n$ dias após), que representa a quantidade de água restante para a próxima semana.

A perda de água semanal foi calculada através das fórmulas:
Perda de água aos sete dias $=($ Massa inicial - Massa aos sete dias antes);

Perda de água aos 14 dias $=$ (Massa aos sete dias após Massa aos 14 dias antes) + Perda de água aos sete dias;

Perda de água aos 21 dias = $($ Massa aos 14 dias após Massa aos 21 dias antes) + Perda de água aos 14 dias.

Posteriormente calculou-se a porcentagem de perda de água semanal através da fórmula:

$\%$ Perda de água semanal $=$ Perda de água aos $n$ dias * 100/ Massa da água colocada inicialmente em cada caixa; sendo $n$ igual a sete, 14 e 21 dias.

Nas datas das contagens, quando se constatou a presença de água condensada sob a tampa das caixas plásticas a mesma foi vertida sobre o substrato após a retirada das plântulas normais.

Foi determinado o tempo despendido para a instalação do teste para cada um dos procedimentos, com cronômetro digital, iniciando a contagem do tempo na semeadura, sobre substrato previamente umedecido, e encerrando-se a contagem de tempo quando as caixas estavam prontas para serem colocadas no germinador.

O procedimento estatístico adotado foi o inteiramente casualizado e a comparação de médias foi feita pelo teste de Tukey a 5\% de probabilidade. Realizou-se transformação dos dados de plântulas anormais em $(x+0,5)^{1 / 2}$ antes das análises, de acordo com as recomendações de Banzatto e Kronka (2006).

\section{RESULTADOS E DISCUSSÃO}

\section{Experimento 1}

A câmara utilizada no trabalho promoveu a desidratação do substrato, havendo perda média de água de 33\%, 59\% e $79 \%$ aos sete, 14 e 21 dias após a instalação do teste, respectivamente. A análise estatística constatou que não houve interação entre os fatores posição vertical das bandejas e posição horizontal (porta, meio e fundo) e nem diferença significativa entre posição horizontal das caixas para a perda de água em todas as avaliações realizadas (Tabela 1). 


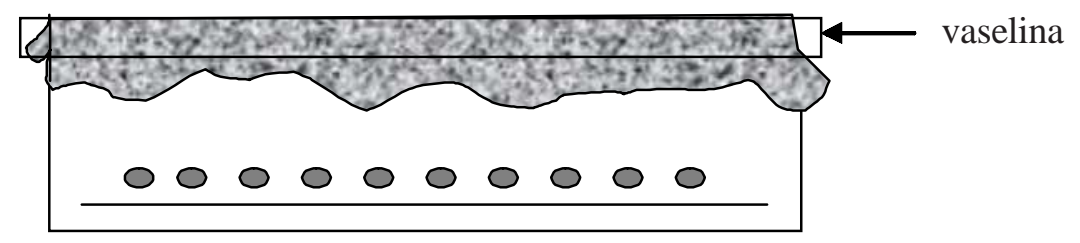

FIGURA 1. Vedação da caixa plástica com vaselina.

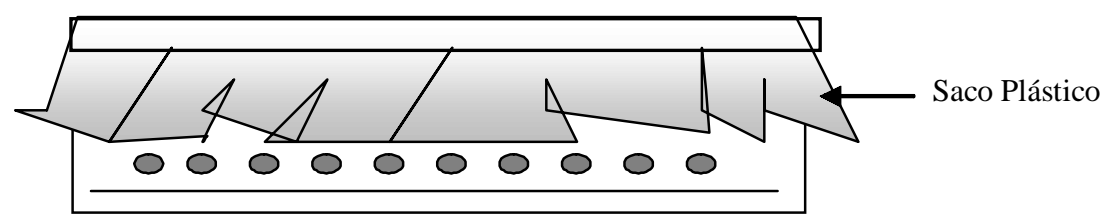

FIGURA 2. Vedação da caixa plástica com saco plástico dobrado em quatro.

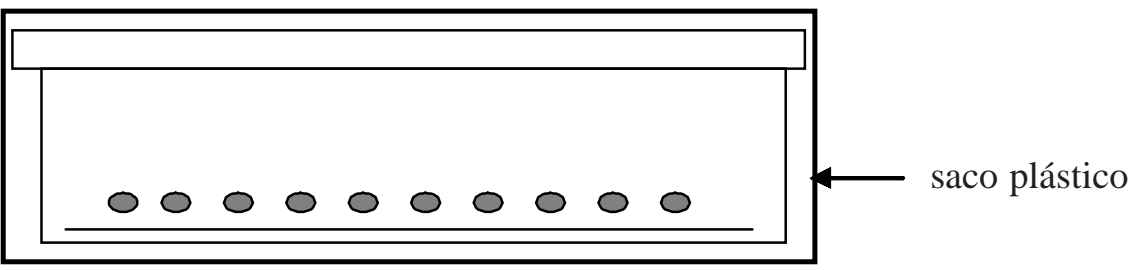

FIGURA 3. Caixa plástica dentro do saco plástico.

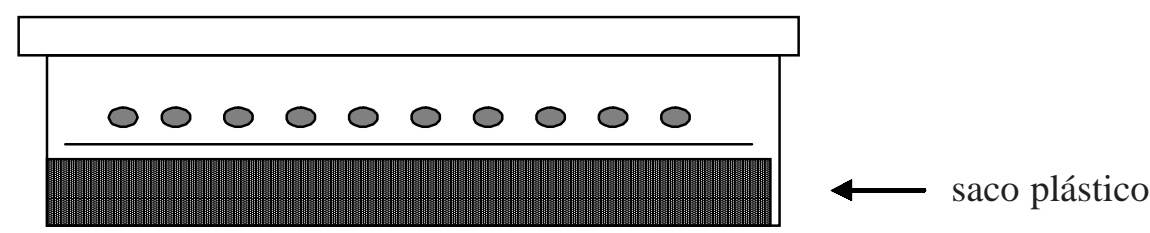

FIGURA 4. Espuma umedecida sob o papel de germinação.

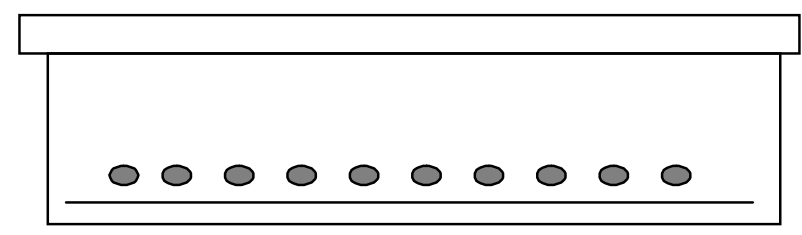

FIGURA 5. Testemunha. 
TABELA 1. Perda de água (\%) do substrato resultante da posição vertical das bandejas no germinador e da posição horizontal das caixas plásticas no germinador.

\begin{tabular}{|c|c|c|c|}
\hline & \multicolumn{3}{|c|}{ Perda de água (\%) } \\
\hline & 7 dias & 14 dias & 21 dias \\
\hline \multicolumn{4}{|l|}{ Bandejas } \\
\hline Primeira & $58,1 \mathrm{~A}^{1}$ & $80,0 \mathrm{~A}$ & $88,5 \mathrm{~A}$ \\
\hline Segunda & $28,4 \mathrm{~B}$ & $54,2 \mathrm{~B}$ & $79,4 \mathrm{AB}$ \\
\hline Terceira & $31,2 \mathrm{~B}$ & $58,8 \mathrm{~B}$ & $80,3 \mathrm{AB}$ \\
\hline Quarta & $41,7 \mathrm{AB}$ & $68,0 \mathrm{AB}$ & $86,7 \mathrm{AB}$ \\
\hline Quinta & $28,2 \mathrm{~B}$ & $56,7 \mathrm{~B}$ & $76,4 \mathrm{AB}$ \\
\hline Sexta & $25,6 \mathrm{~B}$ & $51,2 \mathrm{~B}$ & $74,9 \mathrm{AB}$ \\
\hline Sétima & $25,2 \mathrm{~B}$ & $51,3 \mathrm{~B}$ & $76,1 \mathrm{AB}$ \\
\hline Oitava & $23,3 \mathrm{~B}$ & $44,5 \mathrm{~B}$ & $65,2 \mathrm{~B}$ \\
\hline Nona & $35,7 \mathrm{AB}$ & $63,7 \mathrm{AB}$ & $81,3 \mathrm{AB}$ \\
\hline \multicolumn{4}{|c|}{ Posição horizontal } \\
\hline Porta & 36,6 & 63,7 & 83,2 \\
\hline Meio & 28,4 & 53,7 & 75,4 \\
\hline Fundo & 34,0 & 58,7 & 77,7 \\
\hline $\mathrm{CV} \%$ & 34,06 & 27,73 & 23,13 \\
\hline
\end{tabular}

${ }^{1}$ Médias seguidas da mesma letra na coluna não diferem significativamente pelo teste de Tukey ao nível de 5\% de probabilidade.

TABELA 2. Primeira contagem (\%), plântulas normais (\%) e anormais (\%) do teste de germinação de $B$. brizantha conduzido com diferentes procedimentos de manutenção da umidade do substrato.

\begin{tabular}{lccc}
\hline \multicolumn{1}{c}{ Procedimentos } & Primeira Contagem & Plântulas Normais & Plântulas Anormais \\
\hline Vaselina & $68 \mathrm{~A}^{1}$ & $80 \mathrm{~A}$ & 2 \\
Espuma & $7 \mathrm{~B}$ & $7 \mathrm{~B}$ & 13 \\
Saco plástico & $68 \mathrm{~A}$ & $84 \mathrm{~A}$ & 1 \\
Saco plástico dobrado & $70 \mathrm{~A}$ & $83 \mathrm{~A}$ & 0 \\
Testemunha & $9 \mathrm{~B}$ & $9 \mathrm{~B}$ & 16 \\
\hline \multicolumn{1}{c}{$\mathrm{CV} \%$} & 18,17 & 13,85 & 78,52 \\
\hline
\end{tabular}

${ }^{1}$ Médias seguidas da mesma letra na coluna não diferem significativamente pelo teste de Tukey ao nível de 5\% de probabilidade. 
O efeito da posição da bandeja no germinador aos sete e aos 14 dias (Tabela 1) resultou em maior perda de água pela primeira bandeja, uma perda de água intermediária das bandejas quarta e nona e as demais bandejas apresentaram menor perda de água. Observou-se que a desidratação do substrato foi intensificada com o passar do tempo e aos 21 dias a maior perda de água foi apresentada pela primeira bandeja e a menor perda pela oitava bandeja; as demais foram intermediárias sem diferir das anteriores.

A maior perda de água observada na primeira bandeja pode ser explicada pela localização dos ventiladores da câmara, que ficam logo acima desta bandeja, e embora haja uma cuba com água entre os ventiladores e a primeira bandeja com o objetivo de manter a umidade dentro da câmara, os resultados observados demonstram que este dispositivo não é eficiente.

Dessa forma, a realização do teste de germinação em caixas plásticas, sem uma proteção para evitar a perda de água, sem reumedecimento, torna-se restrita, sendo necessários estudos nesse sentido. Deve-se destacar que foi observada condensação de água sob a tampa das caixas plásticas, o que contribuiu para a perda de água, além do efeito da câmara de germinação.

\section{Experimento 2}

Entre os procedimentos testados, a vedação com vaselina, a colocação da caixa dentro de saco plástico e a vedação com saco plástico dobrado em quatro foram mais favoráveis ao processo de germinação, apresentando resultados superiores aos da testemunha e espuma, com maior velocidade e porcentagem de germinação, verificado pelo teste de primeira contagem e plântulas normais (Tabela 2). Não houve diferença significativa entre os procedimentos testados para a porcentagem de plântulas anormais (Tabela 2).

Esses resultados podem ser atribuídos às menores perdas de água verificadas para esses procedimentos nas três avaliações aos sete, 14 e 21 dias (Tabela 3). Em particular, a utilização de vedação com vaselina possibilitou a menor perda de água aos 14 e 21 dias, seguida pela vedação com saco plástico dobrado e pela colocação da caixa dentro de saco plástico.

Entretanto, ao verificar-se o tempo despendido para a instalação do teste (Tabela 3), observou-se que a vaselina foi o procedimento mais demorado, demandando mais que o dobro do tempo de instalação do que o acondicionamento da caixa em saco plástico e a vedação com saco plástico dobrado, que apresentaram resultados similares aos da vaselina quanto à germinação e primeira contagem e superior aos outros dois procedimentos (Tabela 2).

Quanto à perda de água, a utilização de espuma foi o pior procedimento, inferior inclusive à testemunha (Tabela 3), mas com porcentagens de germinação e de primeira contagem semelhantes às do controle (Tabela 2).

A redução da porcentagem de germinação e a ocorrência de plântulas anormais encontradas no trabalho também foram verificadas em estudos de germinação de sementes de milho (Engelhardt et al., 1966), arroz (Noronha et al., 1967), amendoim (Tanaka et al., 1991) e algodão (Dutra et al., 1995), quando da desidratação do substrato, em condições normais, durante o teste de germinação.

TABELA 3. Perda de água $(\%)$ do teste de germinação de B. brizantha e tempo necessário (segundos) à instalação do teste em diferentes procedimentos de manutenção da umidade do substrato.

\begin{tabular}{lcccc}
\hline \multirow{2}{*}{ Procedimentos } & \multicolumn{3}{c}{ Perda de água (\%) } & Tempo (segundos) \\
\cline { 2 - 4 } & 7 dias & 14 dias & 21 dias & $301 \mathrm{~A}$ \\
\hline Vaselina & $1,7 \mathrm{C}^{1}$ & $3,6 \mathrm{D}$ & $6,56 \mathrm{D}$ & $118 \mathrm{~B}$ \\
Espuma & $97,0 \mathrm{~A}$ & $99,7 \mathrm{~A}$ & $99,3 \mathrm{~A}$ & $142 \mathrm{~B}$ \\
Saco plástico & $5,2 \mathrm{C}$ & $10,1 \mathrm{C}$ & $14,9 \mathrm{C}$ & $128 \mathrm{~B}$ \\
Saco plástico dobrado & $4,7 \mathrm{C}$ & $8,3 \mathrm{C}$ & $12,2 \mathrm{C}$ & $98 \mathrm{~B}$ \\
Testemunha & $89,6 \mathrm{~B}$ & $91,1 \mathrm{~B}$ & $91,3 \mathrm{~B}$ & 18,44 \\
\hline \multicolumn{1}{c}{ CV \% } & 6,76 & 2,66 & 3,46 & \\
\hline
\end{tabular}

${ }^{1}$ Médias seguidas da mesma letra na coluna não diferem significativamente pelo teste de Tukey ao nível de 5\% de probabilidade. 
Também foi verificado por Engelhardt et al. (1966), no trabalho com germinação de sementes de milho sobre papel, em placas de petri, a manutenção da umidade com o acondicionamento das placas em sacos plásticos. Por outro lado, os resultados relativos à baixa eficiência da espuma sob papel, discordam daqueles obtidos por Doni Filho et al. (1985), para Araucaria angustifolia.

Assim, os procedimentos colocação da caixa dentro de saco plástico e vedação com saco plástico dobrado foram eficientes em manter a umidade do substrato, sendo também indicados devido à rapidez de instalação, facilidade de manuseio e maiores possibilidades de padronização e reprodução do método, permitindo que essa metodologia seja inserida na rotina de um Laboratório de Análise de Sementes.

\section{CONCLUSÕES}

A câmara de germinação promove a desidratação desigual do substrato, conforme a posição das caixas; aquelas localizadas na primeira bandeja superior são as mais prejudicadas.

A utilização de vaselina na vedação das caixas plásticas é o procedimento mais eficiente de manutenção da umidade do substrato em testes com duração maior que 14 dias; entretanto, é também o que exige mais tempo para a sua execução.

A colocação das caixas dentro de saco plástico e a vedação com saco plástico dobrado em quatro entre a tampa e a caixa plástica são eficientes na manutenção da umidade do substrato em taxas que não alteram os resultados do teste de germinação de Brachiaria brizantha, e apresentam também rapidez de instalação, facilidade de manuseio e com possibilidade de utilização na rotina de Laboratórios de Análise de Sementes.

\section{REFERÊNCIAS}

ALBRECHT, J.M.F; ALBUQUERQUE, M.C.L.F; MORAES e SILVA, V.S. de. Influência da temperatura e do tipo de substrato na germinação de sementes de cerejeira. Revista Brasileira de Sementes, Brasília, v.8, n.1, p.49-55, 1986.

AMARAL, D.M.I. Padronização de testes em laboratório com sementes florestais. In: SIMPÓSIO BRASILEIRO SOBRE TECNOLOGIA DE SEMENTES FLORESTAIS, 1, 1984, Belo Horizonte. Anais... p. 267-283.
ANDRADE,A.C.S. de; PEREIRA, T.S. Efeito do substrato e da temperaturana germinação e no vigor de sementes de Cedro Cedrela odorata L. (Meliaceae). Revista Brasileira de Sementes, Brasília, v.16, n.1, p.34-40, 1994.

ANTONIOLLI, Z.I.; GIARETTA, H.; ANDRADE, R.N.B.de. Alternativa para substrato na análise de germinação de sementes de cebola (Allium cepa L.). Revista Brasileira de Sementes, Brasília, v.8, n.1, p.29-35, 1986.

BANZATTO, D.A.; KRONKA, S.N. Experimentação agrícola. 4.ed. Jaboticabal: FUNEP, 2006. 237p.

BELCHER, E.W. Influence of substrate moisture level on the germination of seed of selected Pinus species. Seed Science and Technology, Zürich, v.3, n.3, p.597-604, 1975.

BRASIL, Ministério da Agricultura e Reforma Agrária. Regras para análise de sementes. Brasília: SNDA/DNDV/CLV, 1992.365p.

CARVALHO, N.M.; NAKAGAWA, J. Sementes: ciência, tecnologia e produção. 4 ed. Jaboticabal: Funep, 2000. 588p.

CSERESNYES, Z. The germination of Helianthus annuus seeds under optimum laboratory conditions. Sees Science and Technology, Zürich, v.7, n.3, p.319-328, 1979.

DONI FILHO, L.; AMARAL, L.; CERVI, P.H. Métodos para testar o poder germinativo das sementes de Araucária angustifolia (Bert) O. Ktze. Revista Brasileira de Sementes, Brasília, v.7, n.2, p.113-123, 1985.

DUTRA, A.S.; CASTRO, J.R. de; AMARO FILHO, J. Influência da quantidade de água no substrato sobre a germinação de sementes de algodão herbáceo. In: CONGRESSO BRASILEIRO DE SEMENTES, 9, 1995, Florianópolis Anais... Informativo Abrates, Londrina, v.5, n.2, p. 089, 1995.

ENGELHARDT, M.; VICENTE, M.; SILBERSCHMIDT, K. Water requirements for optimum germination in corn (Zea mayz). Arquivos do Instituto Biológico, São Paulo, v.33, n. 3, p. 95-112, 1966.

LIBERAL, O.H.T. Influência da quantidade de água na germinação de semente de cebola (Allium cepa L.). Anais do Seminário Panamericano de Sementes, Brasil, 1963, p.166.

LIMA, D.; GARCIA, L.C. Avaliação de métodos para o teste de germinação em sementes de Acácia manguim Willd. Revista Brasileira de Sementes, Brasília, v.18, n.2, p.180-185, 1996.

MARCOS FILHO, J.; CÍCERO, S.M.; SILVA, W.R. Avaliação da qualidade das sementes. Piracicaba: FEALQ, 1987. 230p.

NORONHA, A.B.; VICENTE, M.; SILBERSCHMIDT, K.; ENGELHARDT, M. Water requirements for optimum germination in rice (Oriza sativa). Arquivos do Instituto Biológico, São Paulo, v.34, n. 3, p. 243-251, 1967. 
OLIVEIRA, A.P.; BRUNO, R.L.A.; ALVES, E.U. Influência do substrato e da temperatura na germinação de sementes de tomate. Revista Brasileira de Sementes, Brasília, v.23, n.2, p.72-77, 2001.

PHANEENDRANATH, B.R. Influence of amount of water in the paper towel on standard germination tests. Journal of Seed Technology, v.5, n.2, p.82-87, 1980.
TANAKA, M.A.S.; MARIANO, M.I.A.; LEÃO, N.V.M. Influência da quantidade de água no substrato sobre a germinação de sementes de amendoim. Revista Brasileira de Sementes, Brasília, v.13, n.1, p.73-76, 1991.

TOLEDO, F.F.de.; PEDREIRA, A.A.S. Quantidade de solução de nitrato de potássio e germinação de sementes de capim colonião. Revista Brasileira de Sementes, Brasília, v.6, n.1, p.61-70, 1984.

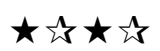

